\title{
Autor e vítima: a vulnerabilidade social de jovens que cometeram atos infracionais em Belo Horizonte*
}

\section{Author and victim: social vulnerability of young people who committed infraction acts in Belo Horizonte}

\author{
Thamyres Cristina Silva Pereira ${ }^{1}$, Jhonatan Natércio dos Reis ${ }^{2}$, \\ Luciana Assis Costa ${ }^{3}$
}

http://dx.doi.org/10.11606/issn.2238-6149.v26i2p258-266

Pereira TCS, Reis JN, Costa LA. Autor e vítima: a vulnerabilidade social de jovens que cometeram atos infracionais em Belo Horizonte. Rev Ter Ocup Univ São Paulo. 2015 maio-ago.;26(2):258-66.

RESUMO: A rápida estruturação de espaços urbanos e a falta de planejamento para provimento de bens de serviços básicos vêm somar-se às precariedades diversas, criando ambientes propícios para a estruturação de atividades criminosas. Em Belo Horizonte, o Centro Integrado de Atendimento ao Adolescente Autor de Ato Infracional contabilizou, em 2010, 9.864 entradas de adolescentes infratores. O suporte e assistência oferecidos no território são fundamentais para compreender o acesso que possuem os indivíduos que nele residem. O Índice de Qualidade de Vida Urbana (IQVU) analisa esta questão. O objetivo do estudo foi identificar o grau de cobertura de bens e serviços urbanos das regiões de Belo Horizonte onde residem os adolescentes que deram entrada no CIA-BH e, posteriormente, correlacioná-lo ao perfil socioeconômico desses jovens. Trata-se de um estudo descritivo baseado em dados secundários, oriundos do IQVU, de 1994 a 2006, somado a dados oficiais sobre o perfil socioeconômico de adolescentes que cometeram atos infracionais, em Belo Horizonte, no período de janeiro a dezembro de 2010 . Os resultados permitem inferir que a maior parte do público estudado está inserida em locais de baixo acesso a insumos básicos e se encontra em condição de vulnerabilidade social. A falta de aparatos sociais pode não explicar ou ter correlação direta com a delinquência juvenil, mas aumenta as oportunidades de envolvimento com a vida do crime.

DESCRITORES: Adolescente; Delinquência juvenil; Vulnerabilidade social; Territorialidade.
Pereira TCS, Reis JN, Costa LA. Author and victim: social vulnerability of young people who committed infraction acts in Belo Horizonte. Rev Ter Ocup Univ São Paulo. 2015 May-Aug.;26(2):258-66

ABSTRACT: The rapid structuring of urban spaces and the lack of planning for the provision of basic services goods come to add to the precariousness, creating favorable environments to the structuring of criminal activities. In Belo Horizonte, the Integrated Center for Care of Juvenile Offenders - CIA$\mathrm{BH}$ recorded the entry of 9,864 young offenders in 2010. The support and assistance offered in the territory are fundamental to understand the kind of access available to those who reside therein. The Urban Life Quality Index (IQVU) analyzes this question. The objective of the study was to identify the degree of coverage of urban goods and services from regions in Belo Horizonte where adolescents who were admitted to the CIA-BH reside and, subsequently, correlate it to the socioeconomic profile of these youths. This is a descriptive study based on secondary data derived from IQVU for 1994-2006, added to the official data on the socioeconomic profile of adolescents who committed infraction acts in Belo Horizonte from January to December 2010. The results allow us to conclude that the majority of the studied public is inserted in locations with low access to basic consumables and is in a condition of social vulnerability. The lack of social apparatuses may not explain or have a direct correlation to juvenile delinquency, but it increases the opportunities for involvement in a life of crime.

KEYWORDS: Adolescent; Juvenile delinquency; Social vulnerability; Territoriality.

\footnotetext{
* Estudo desenvolvido em Trabalho de Conclusão de Curso - TCC.

1. Aluna do curso de Terapia Ocupacional da Universidade Federal de Minas Gerais, Brasil. E-mail: thatacrisgatinha@hotmail.com.

2. Aluno do curso de Terapia Ocupacional da Universidade Federal de Minas Gerais, Brasil. E-mail: jhonatan.n.reis@hotmail.com.

3. Professora Adjunta do Departamento de Terapia Ocupacional, Universidade Federal de Minas Gerais, Brasil.

E-mail: lucianaassis.ufmg@gmail.com.
}

Endereço para correspondência: Alameda da Poesia, 546 - Condomínio Pasárgada. Nova Lima, Minas Gerais, Brasil. CEP: 34000-000. 


\section{INTRODUÇÃO}

$\mathrm{O}$ Estatuto da Criança e do Adolescente (ECA), lei que regulamenta a Constituição de $1988-\mathrm{CF} / 88$, criou condições de exigibilidade para os direitos da criança e do adolescente, conforme expressos no artigo 227 da CF/ $/ 88^{1-2}$. A partir do ECA, desenhou-se uma nova política de proteção e atendimento à infância e adolescência, pautada em direitos cívicos e sociais, inclusive aos adolescentes que cometem atos infracionais. A justiça juvenil, apoiada na "proteção integral" do adolescente prevista pelo estatuto, substituiu a terminologia "crime" por "ato infracional", sendo esse último definido como qualquer ato que infringe o Código Penal, cometido por uma pessoa menor de idade, ou seja, por jovens entre 12 a 18 anos $^{1,3-4}$. O ECA disponibiliza ao juiz seis tipos de medidas socioeducativas classificadas em duas categorias: medidas em meio aberto e as medidas em meio fechado ou de privação de liberdade ${ }^{1-3}$. $\mathrm{O}$ juiz tem um papel central e um poder quase exclusivo na escolha da medida socioeducativa a ser aplicada. O jovem não é julgado apenas tendo como base o ato cometido, mas sua conduta de modo geral, como a periculosidade revelada do jovem, a implicação repetida no mundo do crime, o sentimento de culpabilidade e a estrutura familiar ${ }^{3}$.

As medidas socioeducativas devem assumir um papel de apoio social ao adolescente, oferecendo um suporte protetivo que assegure o desenvolvimento das capacidades de enfrentamento e responsabilização pelos atos cometidos, numa perspectiva educativa e não restrita ao caráter punitivo.

Se por um lado verificam-se, a partir da CF-88, iniciativas do Estado de proteção social ao público infantil no que se refere à ampliação de cobertura das políticas de saúde, educação e assistência social, por outro, pouco tem sido feito no sentido de atender aos direitos básicos do público jovem. Para alguns autores, o jovem no Brasil tem se tornado invisível frente à ação do Estado, exceto nas estatísticas de criminalidade e violência, uso de drogas e de óbitos prematuros ${ }^{2-4}$.

No Brasil, no ano de 2010, existiam 34.157.651 de indivíduos com idade entre 10 e 19 anos, que correspondia a $18 \%$ da população total. Neste mesmo ano, havia 58.764 adolescentes em cumprimento de medida socioeducativa no país*, sendo 18.107 com restrição de liberdade (internação, internação provisória e semiliberdade) e $40.657 \mathrm{em}$ meio aberto. O percentual de adolescentes em cumprimento de medidas em 2010 em relação à população total dessa faixa etária era de $0,17 \%$.

$\mathrm{O}$ Centro Integrado de Atendimento ao Adolescente Autor de Ato Infracional - CIA, de Belo Horizonte/ $\mathrm{MG}^{* *}$, visando o pronto e efetivo atendimento ao adolescente autor de ato infracional, num mesmo espaço físico, por uma equipe interinstitucional, composta por juízes de direito, promotores de justiça, defensores públicos, delegados de polícia, polícia militar e funcionários da Subsecretaria de Estado de Atendimento as Medidas Socioeducativas e da Prefeitura Municipal.), contabilizou, no ano de 2010, 9.864 entradas de adolescentes que cometeram atos infracionais, considerando-se inclusive as entradas dos reincidentes ${ }^{6}$. Tendo em vista a população total de 354.201 de jovens em Belo Horizonte, verifica-se que no ano de $20102,78 \%$ desses indivíduos deram entrada no CIA-BH por envolvimento com a criminalidade.

No que diz respeito aos atos infracionais cometidos por jovens apreendidos em Belo Horizonte em 2010, pode-se ver que o tráfico de drogas representa $27,2 \%$ das ocorrências; o uso de drogas representa $18,5 \%$, seguidos do furto, com 10,7\%; do roubo, com $7,7 \%$ e da lesão corporal, com $6,7 \%$. Os homicídios e tentativas de homicídio contabilizados nesse ano foram 32 casos $(0,4 \%)$ e 24 casos $(0,3 \%)$, respectivamente, do total de 8.009 casos com informação ${ }^{6}$.

Desde sua edição, o ECA vem sendo objeto de análises contraditórias: por um lado, é visto como instrumento eficaz de proteção e de controle social, por outro, é considerado um instrumento legal inaplicável à sociedade brasileira, apoiado no argumento de que " $a$ criminalidade juvenil vem crescendo porque os jovens delinquentes não são punidos ou, quando o são, as medidas socioeducativas são brandas comparativamente à gravidade das ocorrências policiais "’

Essa discussão apresenta-se amiúde, enviesada por um apelo midiático, centrada no agente infrator e restrita ao universo de polícia; por conseguinte, destituída de análises que exprimem de fato a complexidade do fenômeno que envolve a delinquência juvenil. Neste ínterim, pouco se sabe sobre o impacto do ECA no sistema de justiça

\footnotetext{
* O Brasil é o quarto país com o maior número de indivíduos adultos presos, totalizando 715.596 pessoas (CNJ, 2014). A população jovem que cumpre medida socioeducativa representa $8,2 \%$ do total da população presa no Brasil.)

** O CIA foi criado por meio da Resolução-Conjunta $n^{\circ}$ 68, datada de 02 de setembro de 2008, em cumprimento ao disposto no art. 88, inciso V, do Estatuto da Criança e do Adolescente (ECA)
} 
da infância e da adolescência e, em especial, quanto ao efetivo alcance das medidas adotadas pelo poder público em suas atribuições de conter a criminalidade juvenil, no contexto do Estado de Direito 6 .

$\mathrm{O}$ envolvimento de jovens com atos infracionais não é uma temática recente nem particular de países que apresentam níveis elevados de desigualdade social ${ }^{8-9}$.

Abordar as causas dos delitos cometidos por adolescentes é seguramente andar por um terreno movediço e sujeito a debates acirrados. Muitos estudos se vêm aprimorando nessa direção, buscando isolar uma ou mais variáveis que, associadas entre si, responderiam por fortes estímulos à delinquência juvenil (p.66) ${ }^{7}$.

Nessaperspectiva de entendimentomultidimensional do fenômeno, o cometimento de um ato infracional não pode ser explicado pela presença isolada de um fator adverso, ou de risco, mas por meio da complexa cadeia de eventos que impactam na trajetória de vida do jovem ${ }^{9-12}$. Condições estruturais ou macrossociais associam-se a condições pessoais e relacionais que interferem nas oportunidades e escolhas dos jovens, sobretudo daqueles que se encontram em situações de maior risco social ${ }^{13}$.

Este estudo não pretendeu adotar uma linha de análise explicativa sobre a criminalidade juvenil, mas ampliar as informações sobre o perfil socioeconômico do público jovem que cometeu ato infracional em Belo Horizonte, bem como sobre o acesso aos bens e serviços públicos disponíveis nos territórios em que esses jovens residem. Compreender esses espaços é entendê-los como o chão concreto da vida cotidiana, das políticas públicas e do exercício da cidadania, onde o direito a ter direitos é expresso, negado ou reivindicado a partir de lugares concretos: o morar, o estudar, o trabalhar, o divertir-se, o viver saudavelmente, o transitar, o opinar, o participar ${ }^{14}$.

Partiu-se do pressuposto de que a vulnerabilidade social, entendida em suas dimensões econômicas, de acesso a bens e serviços, e societárias, é um dos fatores que oportuniza os jovens a se envolverem em atos infracionais.

A rápida e desordenada estruturação de espaços urbanos e a falta de planejamento para provimento de bens de serviços básicos vêm somar-se à precariedade de naturezas diversas, criando ambientes potencialmente propícios para a estruturação de atividades criminosas ${ }^{15}$. Crescer em comunidades pobres tem sido identificado como um fator de risco para a prática de atos infracionais, aumentando, em duas vezes, a chance de os adolescentes se envolverem em assaltos ou roubos, se comparado a adolescentes de classe média ${ }^{13}$.
Nesse caso, o termo infraestrutura social auxilia-nos na operacionalização do conceito de vulnerabilidade social, a partir do recorte do território, destacando para análise os bens e serviços ofertados e as facilidades de acesso existentes em uma comunidade, tais como: habitação, acesso a crédito, educação, saúde, assistência à infância, meio ambiente bem cuidado e transporte. Engloba, também, a organização social existente na comunidade, que se refere à existência e qualidade de redes de amizades, grupos informais, regras e normas partilhadas pela comunidade ${ }^{16}$.

Para compreender a dimensão territorial na perspectiva de atendimento às necessidades sociais básicas dos adolescentes que deram entrada no CIA, foi utilizado o Índice de Qualidade de Vida Urbana (IQVU) para análise da qualidade do acesso da população a bens e serviços como: saúde, educação, cultura, infraestrutura, segurança, abastecimento, habitação, meio ambiente e serviços urbanos, em sua região e local de moradia, o que possibilita uma comparação entre as diferentes condições de vida existentes em regiões da cidade.

O objetivo do estudo foi identificar a cobertura de equipamentos, bens e serviços urbanos das regiões de Belo Horizonte onde residem os adolescentes que deram entrada no Centro de Internação a Adolescentes Infratores CIA-BH e, posteriormente, correlacioná-la ao perfil socioeconômico desses jovens.

\section{METODOLOGIA}

Trata-se de um estudo quantitativo descritivo baseado em dados secundários publicados em sites oficiais do governo, referentes ao Índice de Qualidade de Vida UrbanaIQVU de Belo Horizonte, relativo aos anos de 1994 a $2006^{17-20}$, somado aos dados sobre o perfil socioeconômico de adolescentes que cometeram atos infracionais, em Belo Horizonte, no período de janeiro a dezembro de 2010. Os períodos indicados na análise do IQVU correspondem ao primeiro e último ano dos dados disponíveis. Em relação aos dados sobre o perfil socioeconômico dos adolescentes, selecionaram-se os de 2010 por serem os dados mais atuais disponibilizados pelo CIA/ $\mathrm{BH}^{6}$.

Considerando a média de idade de 16 anos dos adolescentes que deram entrada no CIA em 2010, verificase que muitos deles nasceram no ano de 1994 e que os dados do IQVU coincidem com o percurso de vida desses jovens, em seu local de moradia. Ressalve-se, todavia, que não necessariamente os jovens moraram durante toda sua vida nos locais classificados pelo IQVU, já que não há disponibilidade de informação sobre o tempo de moradia, conforme dados analisados. No entanto chama atenção 
o fato de que $75 \%$ deles residiam em casas próprias, o que fortalece a chance de estabilidade de residência nos endereços registrados ${ }^{6}$.

O IQVU é um índice intraurbano calculado a partir de uma análise territorial que corresponde às Unidades de Planejamento (UPs) de Belo Horizonte. As UPs foram delimitadas em função dos limites das Regiões Administrativas e/ou dos setores censitários; da existência de grandes barreiras físicas naturais ou construídas que limitam o trânsito e a ocupação; da continuidade e padrão de ocupação. Atualmente, formam um grupo de 80 unidades espaciais intraurbanas, compostas por diversos bairros e aglomerados. No cálculo da série histórica atualizada de 1994-2000, foram mantidas $77 \mathrm{UPs}^{17-18}$.

O índice varia de $0,0 \%$ (zero) a $1,0 \%$ (um ponto percentual); assim, como expressa um atributo positivo - a qualidade de vida urbana -, quanto maior seu valor, melhor a condição da UP. A classificação dos resultados obedece aos seguintes índices: $<0,2$ (Muito baixo); 0,2 a $<0,4$ (Baixo); 0,4 a $<0,6$ (Médio); 0,6 a $<0,8$ (Alto); e $>=$ a 0,8 (Muito alto). Os cálculos atuais consideram 34 indicadores distribuídos em nove variáveis conforme Quadro 1, cada uma com seu respectivo peso ${ }^{17}$.

Quadro 1 - Pesos das variáveis do IQVU utilizados no cálculo da série histórica de 1994-2006

\begin{tabular}{|l|c|}
\hline VARIÁVEL & PESO \\
\hline Abastecimento & 0,08 \\
\hline Cultura & 0,03 \\
\hline Educação & 0,13 \\
\hline Habitação & 0,19 \\
\hline Infraestrutura urbana & 0,17 \\
\hline Meio ambiente & 0,07 \\
\hline Saúde & 0,14 \\
\hline Segurança urbana & 0,08 \\
\hline Serviços urbanos & 0,11 \\
\hline
\end{tabular}

Fonte: Belo Horizonte. Prefeitura Municipal ${ }^{17}$

Esses índices buscam o dimensionamento da qualidade de vida urbana por meio da avaliação de acesso a equipamentos, bens e serviços urbanos, destinados à população de uma determinada região da cidade ${ }^{18}$.

Os dados secundários, utilizados para compreensão do perfil socioeconômico dos adolescentes, foram extraídos do relatório estatístico anual do Centro Integrado de Atendimento ao Adolescente Autor de Ato InfracionalCIA/BH, elaborado pela Vara Infracional da Infância e da Juventude de Belo Horizonte, por meio do Setor de Pesquisa Infracional (SEPI) ${ }^{6}$.

Consta no relatório referente ao ano de 2010 informações sobre o perfil socioeconômico dos adolescentes que cometeram atos infracionais, tais como: idade, escolaridade, local e condição de moradia, situação de trabalho, renda familiar e uso de drogas. Do universo de 9.864 adolescentes que deram entrada no CIA-BH no período de janeiro a dezembro de 2010 , excluíramse as 3.104 reincidências no sistema, o que totalizou um universo de 6.760 adolescentes. Considerando que as informações colhidas foram autodeclaradas, verifica-se uma variação do número total de casos que responderam às questões sobre as dimensões analisadas ${ }^{6}$.

Para este estudo, selecionaram-se, dos dados do CIA, as variáveis que correspondiam àquelas de maior peso contempladas na elaboração do IQVU. São elas: local de habitação, educação, infraestrutura e saúde, sendo esta última relacionada ao uso de drogas; incluem-se também as variáveis trabalho e renda, no sentido de viabilizar a análise entre a cobertura e acesso a equipamentos e as condições socioeconômicas dos adolescentes. Em relação ao local de moradia dos adolescentes, contabilizaram-se apenas bairros que possuíam mais de 80 (oitenta) adolescentes residentes. Esse mínimo foi delimitado no relatório do CIA, ao descrever os locais de moradia dos adolescentes ${ }^{6}$.

\section{RESULTADOS}

Os resultados estão apresentados a partir de duas dimensões: a primeira diz respeito à identificação dos bairros nos quais vivem os adolescentes apreendidos em Belo Horizonte, no ano de 2010, e à classificação dessas regiões, a partir dos dados do IQVU, nos anos de 1994 e 2006. Na segunda dimensão, além de algumas variáveis que foram contempladas no cálculo do IQVU, tais como educação, tipo de moradia, infraestrutura, destacouse também a variável renda, para descrição do perfil socioeconômico dos adolescentes.

O Quadro 2 demonstra os bairros em que residem os adolescentes apreendidos em Belo Horizonte, no ano de 2010, e o nível de classificação dessas regiões conforme o IQVU.

Os dados demonstram que os adolescentes apreendidos residem em bairros de Belo Horizonte, classificados nos índices mais baixos de IQVU (baixo e médio).

Com relação ao perfil dos adolescentes, a média de idade é 15,6 anos, destacando-se o fato de que $74 \%$ encontram-se entre 15 e 17 anos. Em relação a gênero, $84,4 \%$ são do sexo masculino e $15,6 \%$, do sexo feminino ${ }^{6}$. 
Pereira TCS, et al. Autor e vítima: a vulnerabilidade social. Rev Ter Ocup Univ São Paulo. 2015 maio/ago.;26(2):258-66.

Quadro 2 - Bairros de moradia dos adolescentes e IQVU dos respectivos bairros

\begin{tabular}{|l|c|l|c|c|c|}
\hline Bairro de mowradia & $\mathbf{N}^{\mathbf{0}}$ de adolescentes & Região do bairro & $\begin{array}{c}\text { IQVU } \\
\mathbf{1 9 9 4}\end{array}$ & $\begin{array}{c}\text { IQVU } \\
\mathbf{2 0 0 6}\end{array}$ & Última classificação \\
\hline Serra & 310 & Centro-sul & 0,29 & 0,29 & Baixo \\
\hline Alto Vera Cruz & 198 & Leste & 0,23 & 0,30 & Baixo \\
\hline Taquaril & 158 & Leste & 0,23 & 0,30 & Baixo \\
\hline Jardim América & 151 & Oeste & 0,46 & 0,48 & Médio \\
\hline Jardim Vitória & 114 & Nordeste & 0,30 & 0,33 & Baixo \\
\hline Jardim Leblon & 109 & Venda Nova & 0,34 & 0,38 & Baixo \\
\hline Aparecida & 105 & Noroeste & 0,47 & 0,46 & Médio \\
\hline Primeiro de Maio & 104 & Norte & 0,37 & 0,43 & Médio \\
\hline Goiânia & 96 & Nordeste & 0,42 & 0,44 & Médio \\
\hline Céu Azul & 92 & Venda Nova & 0,38 & 0,42 & Médio \\
\hline Nova Granada & 92 & Oeste & 0,46 & 0,48 & Médio \\
\hline São João Batista & 90 & Venda Nova & 0,34 & 0,38 & Baixo \\
\hline São Cristóvão & 90 & Noroeste & 0,47 & 0,46 & Médio \\
\hline Vista Alegre & 80 & Oeste & 0,37 & 0,39 & Baixo \\
\hline Tupi & 80 & Norte & 0,33 & 0,36 & Baixo \\
\hline
\end{tabular}

Fonte: Burgon; Duprez4; Belo Horizonte. Prefeitura Municipa ${ }^{17}$

Quanto à escolaridade do universo de 5.776 adolescentes, $99,5 \%$ são estudantes de escolas públicas e $0,5 \%$, de escolas particulares; $18,2 \%$ possuem ensino fundamental completo e apenas $12 \%$ cursam o ensino médio.

Do total de casos com informação sobre escolaridade, $7,9 \%$ não estudam e $0,1 \%$ é analfabeto. O maior número dos adolescentes, 1.198, que corresponde a $20,7 \%$, encontra-se na $6^{\text {a }}$ série, sendo que $72 \%$ estão no ensino fundamental e 53,9\% ainda não o concluíram ${ }^{6}$.

No quesito moradia, $80,9 \%$ de 3.100 adolescentes moram em casa; $9,6 \%$, em barracão; $5,4 \%$, em apartamento; $3 \%$, nas ruas e $1,2 \%$, em abrigos. Desses adolescentes, $75 \%$ residem em casa própria; $20,4 \%$, em casa alugada; $3,1 \%$, em casa cedida e $0,6 \%$, em moradia ocupada. Em relação ao saneamento básico, 99,6\% possuem acesso à água encanada e energia elétrica; $98,5 \%$ moram em regiões onde há coleta de lixo e $93 \%$ das moradias dispõem de rede de esgoto. Apenas 46,3\% possuem telefone fixo ${ }^{6}$.

No que tange ao uso de drogas, $73,6 \%$ informaram consumir de bebida alcoólica; $64,5 \%$ fazem uso de cigarro; $66 \%$ reportaram consumo de maconha; $33,5 \%$, uso de cocaína; $31,2 \%$, uso de solventes; $4,9 \%$, uso de crack e $2,2 \%$, uso de psicofármacos. Dos 3.100 entrevistados, apenas $8,3 \%$ não usam tais substâncias e $10,1 \%$ declararam já terem feito algum tipo de tratamento antidrogas. Desse universo de adolescentes, $82 \%$ usam drogas e nunca se trataram ${ }^{6}$.
Em relação à situação de trabalho, $20,7 \%$ declararam possuir atividades laborativas e $79,3 \%$ não trabalham. Dos que trabalham, 11,4\% estão inseridos no mercado formal e $88,6 \%$ atuam na informalidade.

A renda dos 640 adolescentes que trabalham se encontra na faixa (mediana) dos $\mathrm{R} \$ 500,00$ mensais, sendo este um valor próximo ao do salário mínimo vigente, no ano da pesquisa. A renda dos jovens variou de $\mathrm{R} \$ 50,00$ até $\mathrm{R} \$ 3.600,00$ mensais $^{6}$.

Em relação à renda familiar dos adolescentes, dos 1.016 informantes, $65 \%$ possuem renda familiar de até três salários mínimos; $11,8 \%$ das famílias não contam com renda e $5,4 \%$ possuem renda menor do que um salário mínimo ${ }^{4}$. Observa-se que grande parcela (44\%) apresentava renda familiar entre um e dois salários mínimos ${ }^{6}$.

\section{DISCUSSÃO}

Os baixos valores do IQVU dos bairros nos quais residem esses adolescentes demonstram que a vulnerabilidade desses jovens está vinculada à restrição de acesso a bens e serviços sociais básicos.

A maioria dos adolescentes envolvidos com a criminalidade é composta por homens na faixa etária dos 15 aos 17 anos, dado que reforça as estatísticas sobre os altos índices de mortalidade de jovens de 15 a 19 anos 
do sexo masculino, tendo como fator principal causas externas relacionadas à violência, com destaque para morte por homicídios e acidentes de trânsito ${ }^{21}$. Vale ressaltar que, no ano de 2010, o homicídio foi a principal causa de morte de adolescentes entre 12 e 17 anos no Brasil, sendo responsável por $45,2 \%$ dos falecimentos de jovens nessa faixa etária. Verifica-se uma diferença discrepante em relação ao percentual de homicídio na população em geral, que atingiu $5,1 \%$ nesse ano, o que revela uma vitimização juvenil de proporções extremamente preocupantes ${ }^{22}$.

Se por um lado os adolescentes correspondem ao grupo com maior índice de mortes precoces por fatores violentos, por outro, estima-se que os menores de 16 a 18 anos são responsáveis por apenas $0,9 \%$ do total dos crimes praticados no Brasil. Se considerados apenas homicídios e tentativas de homicídio, o percentual cai para $0,5 \%{ }^{23}$.

Ainda em relação ao perfil dos adolescentes, os dados também demonstram uma evasão precoce e/ou um déficit importante de escolaridade dos jovens que deram entrada no CIA, considerando que a maioria dos jovens possui até a $6^{\mathrm{a}}$ ou $7^{\mathrm{a}}$ séries do ensino fundamental.

De acordo com os autores analisados, os motivos pelos quais os jovens envolvidos com atos infracionais justificam a desvinculação precoce com o ambiente escolar são: desinteresse $(43,2 \%)$, abandono $(13,5 \%)$, conflitos com outros alunos e ou professores $(13,5 \%)$, fracasso escolar $(5,4 \%)$ e suspensão das aulas $(1,3 \%)$. A evasão escolar pode ainda ser explicada pela ineficácia dos métodos educacionais e pela discriminação por parte dos colegas e professores, que tacham esses jovens de problemáticos, agressivos e outros estereótipos ${ }^{13}$. Uma análise estrutural acerca da reprodução invisível das classes sociais demonstra que os valores imateriais (heranças simbólicas, morais, valorativas) transmitidos aos jovens de classes socioeconômicas mais elevadas, os quais "naturalmente" identificam a escola como o espaço de preparação do indivíduo para a vida, para um mundo produtivo, competitivo e de sucesso, não são universalmente compartilhados pelos jovens de classes mais baixas, dadas as condições de vida e oportunidades a eles ofertados ${ }^{24}$. Esta perspectiva de análise pode explicar a fragilidade dos laços afetivos desses jovens com a escola, tendo em vista que a importância delegada ao estudo não está imersa no cotidiano familiar e na rotina da casa, nem nos valores familiares transmitidos aos filhos. A naturalização da ética individualista e meritocrática obscurece e restringe o entendimento sobre o fracasso escolar dos jovens de classes mais baixas e, não obstante, dos jovens que se encontram no sistema judiciário ${ }^{24}$.
Além das condições socioeconômicas desfavoráveis dos jovens em cumprimento de medidas socioeducativas, vale ressaltar que nas famílias atuais, especialmente de baixa renda, é típica a relação monoparental, de mães solteiras chefes de família, que não contam com o auxílio da figura paterna. $\mathrm{O}$ desafio da conciliação entre o trabalho e a vida doméstica dificulta a participação efetiva junto à dinâmica familiar, o que resulta em fragilidade financeira e educacional ${ }^{25}$.

A baixa escolaridade somada às dificuldades financeiras e restrição à entrada no mercado de trabalho podem oportunizar a inserção desses jovens em atividades ilícitas, como o tráfico, o roubo, o furto e demais infrações, com o intuito de gerar renda, tendo em vista o peso do consumo na construção social da identidade juvenil ${ }^{26}$. Sobre este aspecto, deve-se contextualizar os valores sociais atribuídos às práticas de consumo na sociedade contemporânea, quando essas são vistas como parte do esforço em prol da mobilidade posicional na estrutura social. O processo de mistificação do objeto ofertado pelo mercado, portador de uma alma capaz de dar sentido a quem o possui, induz à construção de um desejo coletivo de posse, sustentado por um ideal liberal de igualdade de condições, enquanto negligencia a estrutura social que restringe uma ampla parcela da população dos meios para alcançá-lo. Jovens socializados numa sociedade de consumo e com baixo poder aquisitivo, tensionados pelo desejo de posse culturalmente compartilhado entre diferentes classes sociais, podem estar mais vulneráveis a ingressar na criminalidade ${ }^{27}$.

Não é possível associar diretamente a condição de família monoparental ao envolvimento de adolescentes no crime, porém sabe-se que essa conjuntura familiar aumenta os fatores de risco, ao unir a dificuldade de prover financeiramente a casa e o cuidado dos filhos, aliada a uma rede de apoio ineficaz ${ }^{13}$.

$\mathrm{O}$ uso de drogas constitui-se um problema de saúde pública no país, sendo frequente entre adolescentes infratores ${ }^{28}$. O estudo corrobora com este fato tendo em vista que $92 \%$ dos adolescentes usam algum tipo de drogas lícitas e ilícitas.

Se comparado à população de adolescentes em geral, de acordo com os dados da PeNSE de 2010,75\% dos adolescentes entre 13 a 15 anos já experimentaram álcool, $25 \%$ bebem regulamente e $9 \%$ relataram ter tido problemas com o álcool. Quanto às drogas, 8,7\% relataram já ter experimentado essas substâncias alguma vez na vida, sendo que a experimentação do álcool e drogas ocorreu precocemente ${ }^{29}$. Um estudo realizado em 1997, com 3.139 estudantes da quinta série do primeiro grau à terceira série do segundo grau de escolas públicas, encontrou um consumo ao longo da vida e nos últimos 30 dias, respectivamente, de 77,7\% e 19,5\% para álcool; $34,9 \%$ 
e 4,6\% para tabaco; $9,2 \%$ e $2,8 \%$ para inalantes; $7,1 \%$ e $1,6 \%$ para tranquilizantes; $6,3 \%$ e $2,0 \%$ para maconha; e $1,9 \%$ e $0,6 \%$ para cocaína ${ }^{30}$. Os dados demonstram que, no caso dos adolescentes envolvidos com atos infracionais, o uso do álcool não apresenta uma discrepância em relação à população jovem geral. No entanto, em relação ao uso de drogas como maconha, cocaína e solventes, os dados demonstram que os jovens envolvidos com a criminalidade apresentam consumo maior do que a população jovem em geral. O levantamento realizado pelo Instituto Latino-Americano das Nações Unidas para Prevenção do Delito e Tratamento do Delinquente (ILANUD) demonstrou que é expressiva a quantidade de usuários de drogas entre os adolescentes privados de liberdade no país: em 2002, 85,6\% faziam uso antes da apreensão, especialmente de maconha $(67,1 \%)$, álcool $(32,4 \%)$, cocaína/crack $(31,3 \%)$ e inalantes $(22,6 \%)^{28}$. Porém esse achado tem a chance de ser subnotificado, especialmente quanto ao uso de drogas pela população de jovens em geral, devido ao fato da investigação se reportar a atos ilícitos.

Fatores como a influência do grupo, a disponibilidade e a presença de drogas na comunidade podem facilitar seu uso por adolescentes envolvidos com a criminalidade, uma vez que o excesso de oferta facilita o acesso a elas ${ }^{28}$.

Um fato interessante é que o uso do crack não atinge de forma significativa a população analisada; é a droga com menor índice de consumo, o que também foi apontado na pesquisa de Martins e Pillon ${ }^{28}$. Os autores também afirmam que, no Brasil, o álcool, o tabaco e a maconha são as drogas mais usadas pelos adolescentes, o que corrobora com os dados analisados nesse estudo. O álcool é uma das substâncias psicoativas mais precocemente consumidas pelos jovens ${ }^{28}$. Estudos internacionais apontam que entre populações de jovens com comportamentos violentos, a presença do álcool, outras drogas e armas aumentam a probabilidade da violência gerar lesões graves e morte ${ }^{31}$. Afirma ainda que, entre adolescentes, o uso de álcool é mais prejudicial do que entre adultos, pois prejudica o julgamento e a habilidade de reconhecer os perigos, dificultando a compreensão dos riscos, o que favorece o envolvimento do indivíduo em comportamentos criminosos, tornando-o vítima ou perpetrador de violência comunitária. A expansão do tráfico e do uso de drogas no país pode estar relacionado à mudança do padrão de criminalidade envolvendo os jovens, especialmente no que se refere ao aumento de crimes violentos ${ }^{7}$. De acordo com os dados do CIA-BH, em 2010, o envolvimento com o tráfico somado ao consumo de drogas foram responsáveis por $45,7 \%$ dos motivos que resultaram na apreensão de adolescentes em Belo Horizonte ${ }^{6}$. Este fato evidencia a necessidade de inserir na agenda do estado a questão do tráfico de drogas no país, no que tange a sua amplitude e estruturas de poder, nas quais esses jovens representam apenas a ponta desse iceberg.

Por fim, vale ressaltar que o perfil socioeconômico apresentado é comum à maioria dos estudos sobre adolescentes apreendidos pelo sistema judiciário brasileiro ${ }^{4}$, o que revela como a desigualdade social é uma condição distintiva de criminalização da juventude.

\section{CONSIDERAÇÕES FINAIS}

Diante do perfil socioeconômico dos adolescentes quecometeramatosinfracionaisederamentradanoCIA-BH, e dos baixos índices de qualidade de vida urbana das regiões nas quais eles residem, pode-se inferir que a grande maioria deles se encontra em condição de vulnerabilidade social, habitando locais de restrito acesso a equipamentos e insumos sociais básicos.

Nesse sentido, verifica-se um perfil homogêneo desses jovens em relação ao fato de residirem em locais carentes de bens e equipamentos urbanos e sociais, de apresentarem defasagem de escolaridade, de pertencerem à família de baixa renda, de estarem inseridos de forma precária no mercado de trabalho, de terem um consumo elevado de drogas ilícitas ou não. Partindo do pressuposto de que o envolvimento com atos infracionais não se encontra restrito às camadas populacionais de baixo poder socioeconômico, esses dados evidenciam que a justiça juvenil reproduz a distinção social no processo de criminalização dos jovens, tendo em vista que apenas adolescentes pobres estão ocupando as vagas do sistema socioeducativo. No entanto não se deve desconsiderar que os jovens que estão em cumprimento de medidas socioeducativas em Belo Horizonte estão expostos a fatores de risco social que tendem aumentar as chances de envolvimento com a criminalidade, seja como vítima, seja como infrator.

Este trabalho possibilitou deduzir que a vulnerabilidade social dos jovens envolvidos com a criminalidade se encontra associada à carência na cobertura de equipamentos e serviços públicos no território e à falta de ações do estado na provisão de direitos sociais básicos; no entanto suscita a necessidade de estudos que levantem novos apontamentos, com o objetivo de detalhar a comunidade onde estes jovens estão inseridos, suas redes de suporte, como eles usam e se apropriam desse espaço, além de como se enquadram na dinâmica e organização das atividades criminosas. 


\section{REFERÊNCIAS}

1. Brasil. Presidência da República. Lei $n^{\circ} 8069$ de 13 de julho de 1990. Dispõe sobre o Estatuto da Criança e do Adolescente e dá outras providencias. Disponível em: http:// www.planalto.gov.br/ccivil_03/leis/18069.htm.

2. Brasil. Constituição da República Federativa do Brasil. 41a ed. 2014. Disponível em: http://bd.camara.gov.br/bd/ handle/bdcamara/17519.

3. Veronese JRP, Lima FS. O Sistema Nacional de Atendimento Socioeducativo (SINASE): breves considerações. Rev Bras Adolesc Conflitualidade (São Paulo). 2009;1(1):26-46.

4. Burgon G, Duprez D. Olhares cruzados sobre o atendimento institucional aos infratores no Brasil. Dilemas Rev Est Conflitos Controle Social (Rio de Janeiro). 2010;3(7):143-79.

5. Brasil. Secretaria de Direitos Humanos. Levantamento nacional do atendimento sócio-educativo ao adolescente em conflito com a lei. Brasília: Secretaria dos Direitos Humanos; 2011. Disponível em: http://www.anajure.org. br/wp-content/uploads/2013/04/LEVANTAMENTONACIONAL-2011.pdf.

6. Brasil. Tribunal de Justiça do Estado de Minas Gerais. Centro Integrado de Atendimento ao Adolescente Autor de Ato Infracional-CIA-BH. Disponível em: http://ftp.tjmg. jus.br/ciabh/relatorio_estatistico_2010.pdf.

7. Adorno S, Bordini EBT, Lima RS. Adolescente e as mudanças na criminalidade urbana. São Paulo Perspect. 1999; 13(4):62-74.

8. Burt MR. Reasons to invest in adolescents. J Adolesc Health. 2002;31:136-52.

9. Shoemaker DJ. Theories of delinquency. An examination of explanations of delinquent behavior. New York: Oxford University Press; 1996.

10. Cunha JM. A saúde do adolescente no contexto da ação socioeducativa. In: Brito LM. Jovens em conflito com a lei. Rio de Janeiro: Ed. UERJ; 2000. p.127-40.

11. Garbarino J. Lost boys. Why our sons turn violent and how we can save them. New York: The Free Press; 1999.

12. Silva DFM, Hutz CS. Abuso infantil e comportamento delinquente na adolescência: prevenção e intervenção. In: Hutz CS. Situações de risco e vulnerabilidade na infância e na adolescência: aspectos teóricos e estratégias de intervenção. São Paulo: Casa do Psicólogo; 2002. p.15185.

13. Gallo AC, Williams LCA. Adolescentes em conflito com a lei: uma revisão dos fatores de risco para a conduta infracional. Psicol Teoria Prática. 2005;7(1):81-95.
14. Koga D. Medidas de cidades: entre territórios de vida e territórios vividos. São Paulo: Cortez; 2003.

15. Beato C, Zilli LF. A estruturação de atividades criminosas. Um estudo de caso. RBCS. 2012;27(80):71-88.

16. Bronzo C. Território como categoria de análise e como unidade de intervenção nas políticas pública. In: Faehel M, Neves JAB. Gestão e avaliação de políticas sociais no Brasil. Belo Horizonte: PUC Minas; 2007. p.91-114.

17. Belo Horizonte. Prefeitura Municipal. Série histórica IQVU 1994-2000-2006: notas metodológicas. Belo Horizonte: Secretaria Municipal de Planejamento, Orçamento e Informação; Secretaria Municipal Adjunta de Planejamento; 2008. Disponível em: portalpbh.pbh.gov.br/pbh/

18. Belo Horizonte. Prefeitura Municipal. IQVU / IVS, experiência de construção e perspectivas de aplicabilidade de índices e indicadores na gestão urbana da qualidade de vida: uma síntese da experiência de Belo Horizonte. Belo Horizonte; 2007. Disponível em: http://portalpbh.pbh.gov.br/pbh/ecp/ contents.do? evento $=$ conteudo $\&$ idConteudo $=19630 \& \mathrm{chPl}$ $c=19630 \&$ termos $=\% 20 \% 20 \% 20$ Nahas.

19. Brasil. Instituto Brasileiro de Geografia e Estatística (IBGE). Síntese de indicadores sociais confirma as desigualdades da sociedade brasileira. Brasília: IBGE; 2002. Disponível em: http://www.ibge.gov.br/home/presidencia/ noticias/12062003indic2002.shtm.

20. Belo Horizonte. Prefeitura Municipal de Belo Horizonte. Orçamento participativo 2009/2010. Cadernos de Metodologia. Disponível em: www.pbh.gov.br/ comunicacao/cartilha_metodologia.pdf.

21. Assis SG, Constantino P. Perspectivas de prevenção da infração juvenil masculina. Cienc Saúde Coletiva. 2005;10(1):81-90.

22. Melo LB, Cano I, organizadores. Índice de homicídios na adolescência: IHA 2009-2010. Rio de Janeiro: Observatório de Favelas; 2012. Disponível em: http://www.unicef.org/ brazil/pt/br_indiceha10.pdf.

23. Brasil. Ministério da Justiça. Secretaria Nacional de Segurança Pública. Disponível em: http://congressoemfoco. uol.com.br/noticias/segundo-ministerio-da-justicamenores-cometem-menos-de-1-dos-crimes-no-pais/.

24. Souza J. A ralé brasileira: quem é e como vive. Belo Horizonte: UFMG; 2009. p.484.

25. Scarpellini M, Carlos VY. Monoparentalidade feminina e vulnerabilidade social: a realidade de mulheres chefes de família no município de Apucarana. In: Anais do II 
Simpósio Gênero e Políticas Públicas. Universidade Estadual de Londrina, 18 e 19 de agosto de 2011. Londrina; 2011. Disponível em: www.unisul.br/wps/wcm/connect/ da2d0ef8-4a35-4f01-9ad3-d6d065dad545/mulhereschefes-familia_mulheres-empreendedoras_projetosextensao-tb.pdf?MOD=AJPERES.

26. Silva JS, Simão MP. A vida no "movimento": crianças e adolescentes no tráfico de drogas. In: Anais do X Encontro de Geógrafos da América Latina, mar. 2005, Universidade de São Paulo; 2005. Disponível em: http:// observatoriogeograficoamericalatina.org.mx/egal10/ Teoriaymetodo/Teoricos/.

27. Melo PB, Assis RV. Mídia, consumo e crime na juventude: a construção de um traçado teórico. Cad CRH (Salvador). 2014;27(70):151-64.

Recebido para publicação: 19.02.14

Aceito para publicação: 23.02.15
28. Martins MC, Pillon SC. A relação entre a iniciação do uso de drogas e o primeiro ato infracional entre os adolescentes em conflito com a lei. Cad Saúde Pública, Rio de Janeiro. 2008;24(5):1112-20.

29. Malta DC, Mascarenhas MDM, Porto DL, Duarte EA, Sardinha LM, Barreto SM, Morais Neto OL.. Prevalência do consumo de álcool e drogas entre adolescentes: análise dos dados da pesquisa nacional de saúde escolar. Rev Bras Epidemiol. 2011;14(1 supl.):136-46.

30. Marques ACPM, Cruz MS. O adolescente e o uso de drogas. Rev Bras Psiquiatr. 2000;22(1 supl.):32-6.

31. Moreira TC, Belmonte EL, Vieira FR, Noto AR, Ferigolo M, Barros MT. A violência comunitária e o abuso de álcool entre adolescentes: comparação entre sexos. J Pediatr (Rio J.). 2008;84(3):244-50. doi: http://dx.doi.org/10.2223/JPED.1795. 